\title{
Distinct and Separable Roles for Endogenous CRY1 and CRY2 within the Circadian Molecular Clockwork of the Suprachiasmatic Nucleus, as Revealed by the Fbxl3 $^{\text {Afh }}$ Mutation
}

\author{
Sneha N. Anand, ${ }^{1}$ Elizabeth S. Maywood, ${ }^{2}$ Johanna E. Chesham, ${ }^{2}$ Greg Joynson, ${ }^{1}$ Gareth T. Banks, ${ }^{1}$ Michael H. Hastings, ${ }^{2}$ \\ and Patrick M. Nolan ${ }^{1}$ \\ ${ }^{1}$ MRC Harwell, Harwell Science and Innovation Campus, Oxfordshire OX11 ORD, United Kingdom, and ${ }^{2}$ Division of Neurobiology, MRC Laboratory of \\ Molecular Biology, Cambridge CB2 0QH, United Kingdom
}

The circadian clock of the suprachiasmatic nucleus (SCN) drives daily rhythms of behavior. Cryptochromes (CRYs) are powerful transcriptional repressors within the molecular negative feedback loops at the heart of the SCN clockwork, where they periodically suppress their own expression and that of clock-controlled genes. To determine the differential contributions of CRY1 and CRY2 within circadian timing in vivo, we exploited the $N$-ethyl- $N$-nitrosourea-induced afterhours mutant $F b x l 3^{A f h}$ to stabilize endogenous CRY. Importantly, this was conducted in CRY2- and CRY1-deficient mice to test each CRY in isolation. In both CRY-deficient backgrounds, circadian rhythms of wheel-running and SCN bioluminescence showed increased period length with increased $F b x / 3^{A f h}$ dosage. Although both CRY proteins slowed the clock, CRY1 was significantly more potent than CRY2, and in SCN slices, CRY1 but not CRY2 prolonged the interval of transcriptional suppression. Selective CRY-stabilization demonstrated that both CRYs are endogenous transcriptional repressors of clock-controlled genes, but again CRY1 was preeminent. Finally, although $\mathrm{Cry}^{-/-} ; \mathrm{Cry2}^{-/-}$mice were behaviorally arrhythmic, their SCN expressed short period $(\sim 18 \mathrm{~h})$ rhythms with variable stability. Fbxl3 ${ }^{A f h / A f h}$ had no effect on these CRY-independent rhythms, confirming its circadian action is mediated exclusively via CRYs. Thus, stabilization of both CRY1 and CRY2 are necessary and sufficient to explain circadian period lengthening by $F b x l 3^{A f h / A f h}$. Both CRY proteins dose-dependently lengthen the intrinsic, high-frequency SCN rhythm, and CRY2 also attenuates the more potent period-lengthening effects of CRY1. Incorporation of CRY-mediated transcriptional feedback thus confers stability to intrinsic SCN oscillations, establishing periods between 18 and $29 \mathrm{~h}$, as determined by selective contributions of CRY1 and CRY2.

\section{Introduction}

The principal pacemaker in the brain, the suprachiasmatic nucleus, is an extremely precise and effective biological clock. The daily rhythms of behavior and physiology that it drives synchronize and adapt an individual to the solar cycle of day and night (Brown et al., 2012). Consequences of disrupted circadian timekeeping include behavioral, endocrine, metabolic, reproductive, and immune function disturbances (Barnard and Nolan, 2008; Delezie and Challet, 2011; Sehgal and Mignot, 2011; Kennaway et al., 2012; Logan and Sarkar, 2012). Nevertheless, single gene disturbances with dramatic effects on circadian function are extremely rare. This is because many of the regulatory core clock

Received 0ct. 22, 2012; revised March 1, 2013; accepted March 4, 2013.

Author contributions: M.H.H. and P.M.N. designed research; S.N.A., E.S.M., J.E.C., G.J., and G.T.B. performed research; S.N.A., E.S.M., J.E.C., and G.T.B. analyzed data; S.N.A., E.S.M., M.H.H., and P.M.N. wrote the paper

This work was supported by the MRC and by the 6th Framework Project EUCLOCK (№. 018741).

The authors declare no competing financial interests.

Correspondence should be addressed to Patrick. M. Nolan, MRC Harwell, Harwell Science and Innovation Campus, 0xfordshire 0X11 ORD, UK. E-mail: p.nolan@har.mrc.ac.uk.

DOI:10.1523/JNEUROSCI.4950-12.2013

Copyright $\odot 2013$ the authors $\quad 0270-6474 / 13 / 337145-09 \$ 15.00 / 0$ components exist as paralogous pairs or gene families, often serving partially overlapping functions (Looby and Loudon, 2005). Clarification of these gene-specific functions is therefore a prerequisite for understanding the molecular basis of the clock and its relevance to disease.

The mammalian cryptochrome proteins, CRY1 and CRY2, are the key negative transcriptional regulators within the transcriptional feedback loops that constitute the core molecular pacemaker of the suprachiasmatic nucleus (SCN) (Vitaterna et al., 1999; van der Horst et al., 1999). They inhibit the expression of their own genes and also of period genes $(\operatorname{Per} 1,2,3)$ by opposing E-box mediated transactivation by CLOCK:BMAL1 heterodimers (Kume et al., 1999). But although their sequence conservation is extremely high, wheel-running analysis of null mutations highlights surprising and opposite effects on circadian output pathways. Circadian period is shorter in $\mathrm{Cryl}^{-1-}$ mice (consistent with the negative action of Cryl at E-box elements) while, paradoxically, it is longer in $\mathrm{Cr} y 2^{-/-}$mice. However, $\mathrm{Cryl}^{-1-}$;Cry $2^{-/-}$mice show complete arrhythmicity in constant darkness indicating that they play distinct but at least partially overlapping roles. Examination of these roles has relied princi- 
pally on in vitro overexpression approaches in cell lines (Griffin et al., 1999; Kume et al., 1999). Although useful in mapping general properties, such studies are not able to reveal the selective and particular contributions of endogenous CRY1 and CRY2 within the dynamic environment of the SCN circadian clockwork, not least because overexpression in cell lines inevitably suppresses the very circadian dynamics that are the point of experimental interest. Crucially, transcriptional repression by cryptochromes is circadian time dependent, meaning that efficient mechanisms need to be in place to regulate CRY protein levels. The discovery of multiple mutations in Fbxl3 (Godinho et al., 2007; Siepka et al., 2007) has highlighted the importance of their timely proteasomal degradation. Both mutations in $\mathrm{Fbxl3}$ cause severe period lengthening of circadian behavior and exhibit a reduced affinity for endogenous CRY proteins resulting in their stabilization across the circadian cycle. Effectively, this allows one to investigate CRY function in the mammalian oscillator by studying the effect of CRY-related transcriptional repression at times when they would normally be curtailed. Moreover, consequent effects on transcription of other core oscillator genes and effects on output rhythms can also be assessed. We therefore generated double and triple Cry1/Cry2/Fbxl3 mutants to investigate behavioral and molecular consequences of stabilizing either CRY1 or CRY2 proteins in mice lacking the alternative form of $\mathrm{Cry}$.

\section{Materials and Methods}

Animals. Animal studies described in this paper were performed under the guidance issued by the Medical Research Council in Responsibility in the Use of Animals for Medical Research (July, 1993) and Home Office Project Licenses \#30/2686 and 80/1874. Cry $1^{-1-}$ and Cry $2^{-1-}$ mice were kindly provided by G. T. van der Horst (Erasmus MC, Rotterdam, The Netherlands) (van der Horst et al., 1999). These lines were crossed to $F b x l 3^{A f h / A f h}$ mice to generate double heterozygous and homozygous mutants. For SCN slice studies, all combinations of genotypes were generated in crosses to PER2::LUC mice $\left(P e r 2^{T m 1 J t}\right)$. All lines were maintained on a C57BL/6J background. Mice were housed in individually ventilated cages under 12/12 h light/dark (LD) conditions with food and water available ad libitum. For circadian recording, mice were housed in individual cages equipped with running wheels in light-tight ventilated chambers (Bacon et al., 2004). Mice of either sex were maintained for $7-10 \mathrm{~d}$ in LD conditions and were subsequently transferred to constant dark (DD) conditions for 10-14 d. Wheel running data were collected and analyzed using Clocklab (Actimetrics Software).

Bioluminescence imaging. SCN organotypic slice cultures from 10-14d-old pups (sex not determined) were prepared and bioluminescence emission recorded using photomultipliers and CCD cameras (Hamamatsu) as described previously (Maywood et al., 2006). Rhythmicity and period were assessed with BRASS software (A. Millar, University of Edinburgh, Edinburgh, UK and M. Straume, University of Virginia, Charlottesville, VA).

Genotyping. DNA was extracted from ear biopsies using $100 \mu \mathrm{l}$ of $50 \mathrm{~mm}$ $\mathrm{NaOH}$ at $95^{\circ} \mathrm{C}$ for 90 min and buffered with $10 \mu \mathrm{l}$ of $1 \mathrm{~m}$ Tris pH7.5. Fbxl3 $3^{A f h / A f h}$ and PER2::LUC mice were genotyped using assays as previously described (Yoo et al., 2004; Godinho et al., 2007). For Cryl, genespecific primers were GTGTCTGGCTAAATGGTGG (forward) and CAGGAGGAGAAACTGACGCACT (reverse) and an additional Neocassette-specific forward primer, TGAATGAACTGCAGGACGAG. Standard PCR conditions were used to amplify products using the PCR cycle $\left(94^{\circ} \mathrm{C}\right.$ for $30 \mathrm{~s}, 61^{\circ} \mathrm{C}$ for $60 \mathrm{~s}, 72^{\circ} \mathrm{C}$ for $\left.60 \mathrm{~s}\right) \mathrm{X} 35$. Wild-type allele product size was $1600 \mathrm{bp}$ and mutant product size was $2200 \mathrm{bp}$. For Cry2, gene-specific primers were CCAGAGACGGGAAATGTTCTT (forward) and GCTTCA TCCACATCGGTAACTC (reverse) and an additional Neo-cassette specific forward primer, GAGATCAGCAGCCTCTGTTCC. Standard PCR conditions were used to amplify products using the PCR cycle $\left(95^{\circ} \mathrm{C}\right.$ for $30 \mathrm{~s}, 55^{\circ} \mathrm{C}$ for $30 \mathrm{~s}, 72^{\circ} \mathrm{C}$ for $90 \mathrm{~s}$ ) X35. Wild-type allele product size was $550 \mathrm{bp}$ and mutant product size was $310 \mathrm{bp}$. $q P C R$. Liver and cerebellum from wild-type and double homozygous mutant male mice $(n=3)$ were dissected at zeitgeber times (ZT) 3, 7, 11, 15,19 , and 23 , snap frozen on dry ice, and stored at $-80^{\circ} \mathrm{C}$. RNA was extracted using the standard Trizol (Life Technologies) extraction protocol. Total RNA concentration was determined using a Nanodrop ND1000 (Thermo Fisher Scientific).

Gene expression was determined using SYBR green-based real-time PCR (RT-PCR) assays using the following primers: Bmal1 (forward: CCGTGC TAAGGATGGCTGTT, reverse: TTGGCTTGTAGTTTGCTTCTGTGT), Cryl (forward: GTGGATCAGCTGGGAAGAAG, reverse: CACAGGGCAG TAGCAGTGAA), Cry2 (forward: TGACCTAGACAGAATCATCGAACT G, reverse: GGCTGATGAGGGCCTGAA), Dbp (forward: GAGCCTTCTG CAGGGAAACA, reverse: GCCTTGCGCTCCTTTTCC), Per1 (forward: CC CCTGCCTCCCAGTGA, reverse: CTGAAAGTGCATCCTGATTGGA), Per2 (forward: AGCTACACCACCCCTTACAAGCT, reverse: GACACGGC AGAAAAAAGATTTCTC), Rev-er $\alpha \alpha$, (forward: CGTTCGCATCAATCGC AACC, reverse: GATGTGGAGTAGGTGAGGTC), and the housekeeping control gene Rpl13a (forward: TGCTGCTCTCAAGGTTGTTC, reverse: TG CTTCTTCTTCGATAGTGC). Reverse transcription (RT) was performed using the Superscript III first-strand synthesis for qPCR kit (Life Technologies) with $1 \mu \mathrm{g}$ of total RNA as template. RT-PCRs were performed in triplicate using $10 \mu \mathrm{l}$ of $2 \times$ Power SYBR Green PCR master mix (Life Technologies), $2 \mu$ l of product from the RT reaction (diluted 1:4), $1 \mu \mathrm{l}$ of 2 $\mu \mathrm{M}$ primer mix (containing both the forward and reverse primers), and $7 \mu \mathrm{l}$ of nuclease-free water. A sample minus reverse transcription buffer was used as a negative control for the RT-PCRs. All of the negative controls used failed to reach threshold by 45 cycles.

RT-PCRs were run on a 7500 Fast Real-Time PCR System (Applied Biosystems). Relative expression was calculated using the standard $2^{-(\Delta \Delta(\mathrm{Ct}))}$ relative expression method. Relative expression of individual samples was normalized to that of Rpl13a.

Protein extraction, antibodies, and Western blotting. Cerebellum from wildtype and double homozygous mutant male mice $(n=3)$ was dissected at ZT $3,7,11,15,19$, and 23 , snap frozen on dry ice, and stored at $-80^{\circ} \mathrm{C}$. For CRY2 studies, tissue aliquots (50-70 mg) were lysed in $1 \mathrm{ml}$ of RIPA buffer ( $1.75 \mathrm{~g}$ of $\mathrm{NaCl}, 2 \mathrm{ml}$ of NP40, $10 \mathrm{ml}$ of Tris $\mathrm{pH} 7.51 \mathrm{~m}, 2 \mathrm{ml}$ of $10 \%$ SDS, 10 $\mathrm{ml}$ of $10 \%$ sodium deoxycholate, $176 \mathrm{ml}$ of $\mathrm{H}_{2} \mathrm{O}$ ) with protease and phosphatase inhibitors (Roche) using FastPrep lysing matrix D (MP Biomedicals). Protein concentrations in lysates were measured using Bradford reagent (Sigma). Two times LDS sample loading buffer (2.5 $\mu$ l; Invitrogen) and reducing agent ( $1 \mu \mathrm{l}$; Invitrogen) were added to $10 \mu \mathrm{g}$ of protein lysates. Samples were heat-denatured and loaded on $4-12 \%$ Bis-Tris NuPAGE precast gels (Invitrogen). For CRY1 studies, proteins were extracted from snapfrozen tissues using $2 \times$ Laemelli buffer $(6 \times$ is $1.2 \mathrm{~g} \mathrm{SDS}, 6 \mathrm{mg}$ bromophenol blue, $4.7 \mathrm{ml}$ of Glycerol, $1.2 \mathrm{ml}$ of Tris $0.5 \mathrm{~m} \mathrm{pH} 6.8,4.1 \mathrm{ml}$ of $\mathrm{ddH}_{2} \mathrm{O}$, and reducing agent $\beta$-mercaptoethanol or DTT). Samples were sonicated (Health-Sonics) for $30 \mathrm{~min}$ and then centrifuged for $15 \mathrm{~min}$ at $4^{\circ} \mathrm{C}$. Five microliters of aliquots of heat-denatured samples were directly loaded on the gel. Electrophoresis and Western blot were performed using the Invitrogen system. NuPAGE 4-12\% Bis-Tris gels were run in MOPS running buffer and then transferred to PVDF membrane using a semidry blotter (Bio-Rad). Membranes were first incubated in blocking solution [5\% dried nonfat milk prepared in Tris-buffered saline containing $0.1 \%$ Tween 20 (TBST)] at $4^{\circ} \mathrm{C}$ for $24 \mathrm{~h}$ on a shaking platform, washed with TBST, incubated with custommade antibodies to CRY1 or CRY2 (1:500 in blocking solution overnight at $4^{\circ} \mathrm{C}$ ) or with anti-actin (Abcam, 1:80,000, $30 \mathrm{~min}$ at room temperature), washed with TBST, and finally incubated with HRP-conjugated anti-rabbit (Bio-Rad, 1:3000 in blocking solution for $1 \mathrm{~h}$ at room temperature) or antimouse IgG (Sigma, 1:10,000, $1 \mathrm{~h}$ at room temperature). CRY1 and CRY2 antibodies were raised against murine peptide sequences SQEEDAQSVGPKVQRQSSN and VTEMPTQEPASKDS, respectively. After washing, Amersham ECL Plus Western blot Detection Kit (GE Healthcare) was used for signal detection using the UVP ChemiDoc-It Imaging System.

Statistical analysis. For wheel-running and SCN slice studies, two-way ANOVA with Bonferroni post hoc analysis was performed. For protein studies, the relative expression of CRY protein normalized to $\beta$-actin across all time points in wild-type and $\mathrm{Cr}^{-1-} ; \mathrm{Fb} x \mathrm{l} 3^{\mathrm{Afh} / \mathrm{Afh}}$ double mutants was analyzed by two-way ANOVA with time and genotype as factors. For gene expression analysis, two-way ANOVA with Bonferroni 
A

CRY2

CRY1
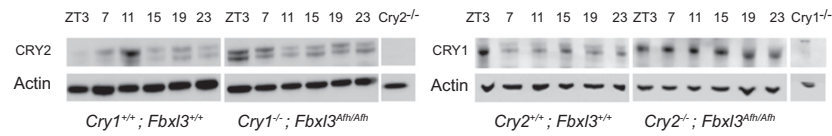

B

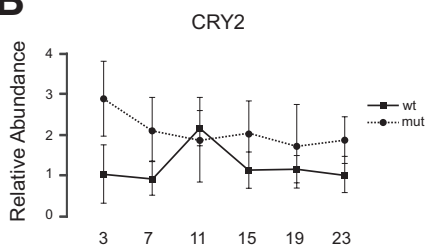

Zeitgeber Time (ZT)

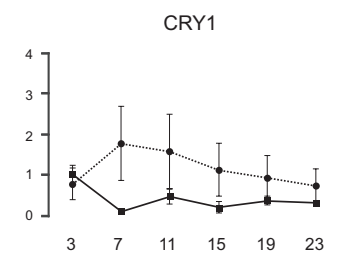

Zeitgeber Time (ZT)

Figure 1. Circadian expression of cryptochrome proteins is stabilized in cerebellum of double mutant mice. $\boldsymbol{A}$, Cerebellar tissue was collected from 6 ZT points. Proteins extracted from wildtype, $\mathrm{Cry}^{-/-} ; \mathrm{Fbx} / 3^{A f h / A f h}$ and $\mathrm{Cry} 2^{-/-} ; \mathrm{Fb} \times 13^{A f h / A f h}$ double mutants were quantitated and equal amounts loaded on 4-12\% Bis-Tris gels. Cerebellum from appropriate cryptochrome null mutant samples were used as a negative control. Western blots were probed with either antiCRY2 or anti-CRY1 primary antibodies with anti- $\beta$-actin antibody used as a reference protein. Representative blots are shown. $\boldsymbol{B}$, Quantified cryptochrome protein levels, lower band in case of $C R Y 2$, were first normalized to the endogenous control $\beta$-actin. Normalized values were then plotted relative to levels in the wild-type sample at ZT3 (assigned an arbitrary value of 1). Each time point shown in the graph is an average of four independent samples (mean \pm SEM). In both sets of double mutant samples, levels of the appropriate CRY protein are upregulated and stabilized across the cycle. A two-way ANOVA test reveals that cryptochrome levels in mutants are significantly stabilized across time relative to the appropriate control set.

post hoc analysis was performed using genotype and time as factors. For Cry 1 and Cry 2 expression analysis, two-way ANOVA was performed with no post hoc analysis. All data were analyzed using SPSS statistical software.

\section{Results}

Circadian behavioral effects of selective and independent stabilization of endogenous CRY1 or CRY 2 by Fbxl3 ${ }^{\text {Afh/Afh }}$

In otherwise wild-type mice, $F b x l 3^{A f h / A f h}$ jointly stabilizes CRY1 and CRY2 proteins over the circadian cycle (Godinho et al., 2007). To test for independent actions of Fbxl3 $3^{A f h / A f h}$ on the individual proteins, its effects on CRY1 and CRY2 were tested in $\mathrm{Cry} 2^{-/-}$and $\mathrm{Cry} 1^{-/-}$mice, respectively. In cerebellum samples collected around the light-dark cycle, the Afh mutation, in the absence of CRY1, significantly upregulated and stabilized CRY2 (lower CRY2 band) compared with wild-type (two-way ANOVA, genotype effect; $F_{(1,36)}=4.7, p=0.036$; time effect; $F_{(5,36)}=$ $0.307, p=0.906$, Fig. $1 A, B$, left). Similarly, in the absence of CRY2, Fbxl $3^{A f h / A f h}$ significantly upregulated and stabilized CRY1 protein levels across time (two-way ANOVA, genotype effect; $F_{(1,36)}=4.8, p=0.035$; time effect; $F_{(5,36)}=0.247, p=0.938$, Fig. $1 A, B$, right). Having established that $F b x l 3^{A f h}$ has independent biochemical effects on both CRY1 and CRY2, i.e., stabilization in the absence of the alternative paralogue, we then examined the consequences of this selective stabilization on circadian behavior.

To assess the behavioral effects of stabilized CRY2 in the absence of CRY1, wheel-running rhythms were recorded in mice with each of the nine allelic combinations of Cry1 null (or WT) and $F b x l 3^{A f h}$ (or WT) (Fig. 2A,B). All genotypes entrained to the initial $12 / 12 \mathrm{~h} \mathrm{LD}$ schedule for $7 \mathrm{~d}$. Upon transfer to DD, the animals exhibited clear free-running rhythms for 2 weeks, with genotypically specific periods, significantly affected by both Cry 1 and Fbxl3 alleles (two-way ANOVA: $F_{(2,113)}=33.4, p=0.0001$ and $F_{(2,113)}=76.2, p=0.0001$, respectively). There was also a significant interaction between the two genotypes $\left(F_{(4,113)}=6.2, p=0.0001\right)$.

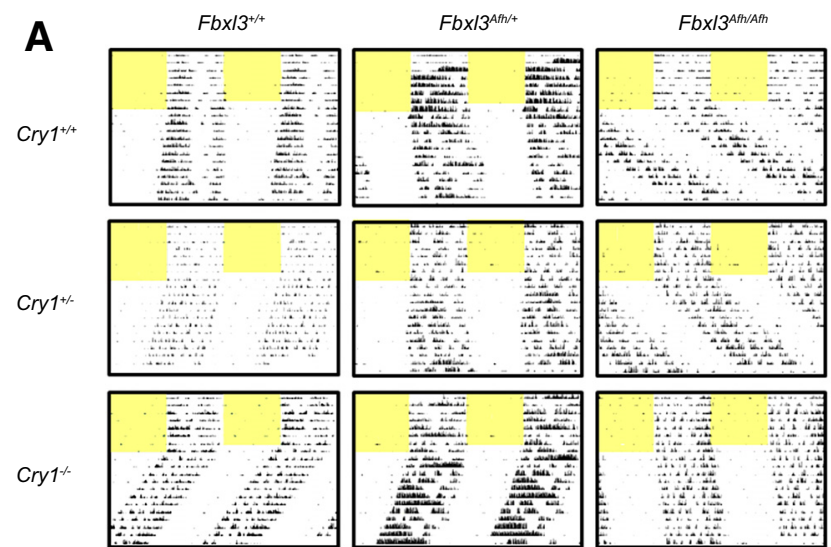

B

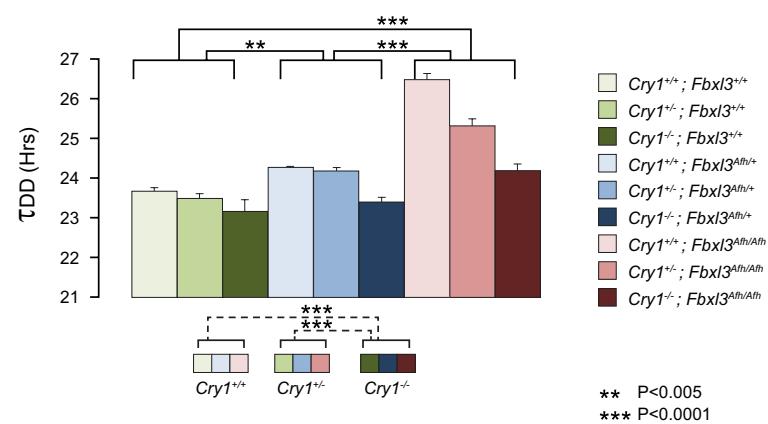

Figure 2. Effects of $\mathrm{Cry} 1^{-/-}$and $\mathrm{Fb} \times 3^{A f h / A f h}$ alone and in combination on wheel-running behavior in mice. $\boldsymbol{A}$, Representative double-plotted actograms for all genotype combinations of Cry $1^{-1-} ; \mathrm{Fbx} / 3^{A f h / A f h}$ double mutant crosses. Animals were first entrained to a $12 \mathrm{~h}$ LD schedule for $7 \mathrm{~d}$ followed by a 2 week period in constant darkness. Shaded regions indicate where lights are on and black vertical bars represent bouts of wheel-running activity. $\boldsymbol{B}$, Free-running period in $\mathrm{DD}\left(\tau_{\mathrm{DD}}\right)$ for all 9 genotypes from double mutant crosses (mean $\pm \mathrm{SEM}, n=10$ per group). Statistical significance was determined by 2-way ANOVA with Bonferroni post hoc analysis. Significant post hoc results are denoted separately for Cry-dependent (dashed line in inset; comparing the set of three lighter hued columns with the three medium and three dark) and $\mathrm{Fb} \times 13^{A f h}$-dependent (solid line in main panel; comparing the set of three green columns with the three blue and three red) effects.

Whereas $F b x l 3^{A f h}$ significantly lengthened free-running period in a wild-type background (wild-type $=23.68 \pm 0.09 \mathrm{~h} ; \mathrm{Fbxl3} 3^{\text {Afh } / \text { Afh }}=$ $26.48 \pm 0.16 \mathrm{~h}, \Delta=2.80 \mathrm{~h}), \mathrm{Cry1} 1^{-/-}$significantly shortened it (wild-type $=23.68 \pm 0.09 \mathrm{~h} ; C r y 1^{-1-}=22.89 \pm 0.07 \mathrm{~h}, \Delta=0.79 \mathrm{~h}$ ). More surprisingly, with the loss of Cryl, the Fbxl3 ${ }^{\text {Afh }}$ allele retained its ability to lengthen free-running period, although this effect mediated via stabilization of CRY2 was dramatically attenuated in the $\mathrm{Cry} 1^{-/-}$animals when compared with wild-types $\left(\mathrm{Cry} 1^{-/-}\right.$; $\mathrm{Fbxl3}^{+/+}=22.89 \pm 0.07 \mathrm{~h} ; \mathrm{Cry}^{-/-} ; \mathrm{Fbxl3} 3^{\text {Afh/Afh }}=24.19 \pm 0.16 \mathrm{~h}$, $\Delta=1.30$ h). Thus, in the absence of CRY1, circadian stabilization of endogenous CRY2 lengthened period, but not as efficiently as in the combined presence of both CRY2 and CRY1 in wild-type mice (1.30 vs $2.80 \mathrm{~h}$, respectively).

In the converse test, the behavioral effects of $F b x l 3^{A f h}$ on endogenous CRY1 were determined in the progressive absence of CRY2 (Fig. $3 A, B$ ). Two-way ANOVA revealed significant main effects of both Cry2 and Fbxl3 ${ }^{A f h}$ genotypes $\left(F_{(2,113)}=21.1, p=\right.$ 0.0001 and $F_{(2,113)}=361.2, p=0.0001$, respectively) both of which lengthened period: deficiency of CRY2 thus contrasting with the accelerating effect of CRY1 deficiency. There was also a significant interaction between genotypes $\left(F_{(4,113)}=2.64\right.$, $p=0.038)$. Period lengthening by the Cry2 allele was small, but dose-dependent and significant in both heterozygotes and homozygotes (wild-type $=23.68 \pm 0.09 \mathrm{~h} ; \mathrm{Cry}^{-/-}=24.24 \pm$ $0.08 \mathrm{~h}, \Delta=0.56 \mathrm{~h})$. In double mutants, the ability of the Fbxl3 ${ }^{A f h}$ 
A

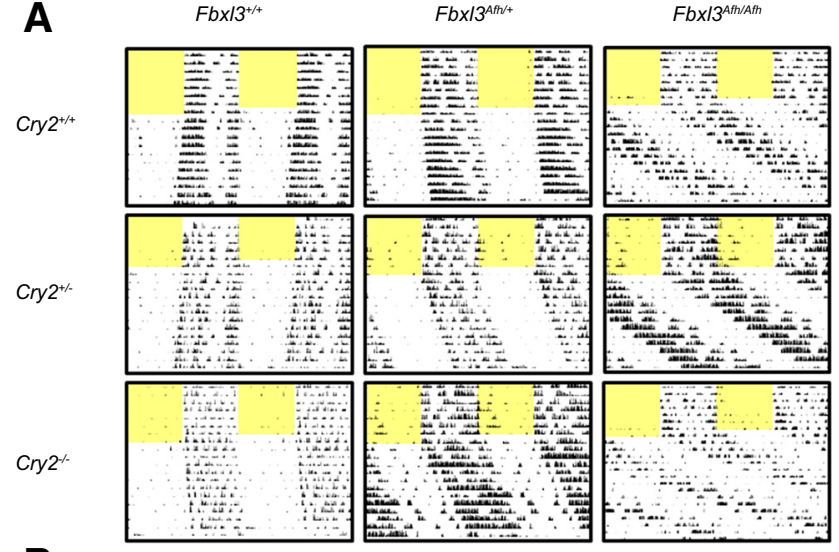

B

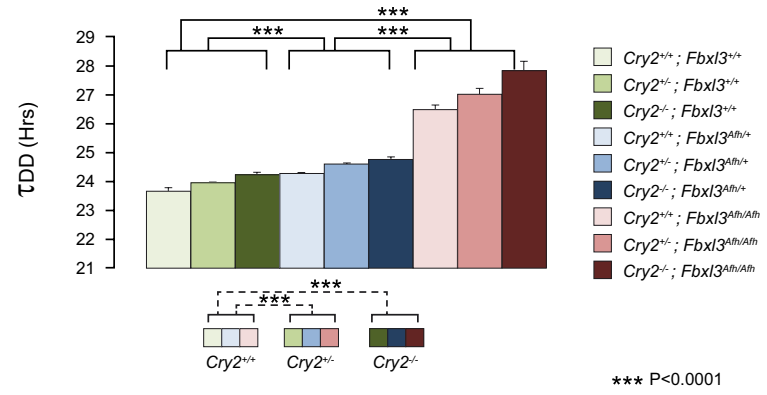

Figure 3. Effects of $\mathrm{Cry} 2^{-/-}$and $\mathrm{Fbx} / 3^{A f t / A f h}$ alone and in combination on wheel-running behavior in mice. $\boldsymbol{A}$, Representative double-plotted actograms for all genotype combinations of $\mathrm{Cry}^{-/-}$; $\mathrm{Fbx} / 3^{\text {Aft/Afh }}$ double mutant crosses. Animals were first entrained to a $12 \mathrm{~h} \mathrm{LD}$ schedule for $7 \mathrm{~d}$ followed by 2 week period in constant darkness. Shaded regions indicate where lights are on and blackvertical bars represent bouts of wheel-running activity. $\boldsymbol{B}$, Free-running period in DD for all 9 genotypes from double mutant crosses (mean \pm SEM, $n=10$ per group). Statistical significance was determined by two-way ANOVA with Bonferroni post hoc analysis. Significant posthoc results are denoted separately for Cry-dependent (dashed line in inset; comparing the set of three lighter hued columns with the three medium and three dark) and $\mathrm{Fbx} / 3^{A \text { At }}$-dependent (solid line in main panel; comparing the set of three green columns with the three blue and three red) effects.

allele to lengthen period in constant darkness was retained $\left(\mathrm{Cry}^{-/-} ; \mathrm{Fbxl3}^{+/+}, 24.24 \pm 0.08 \mathrm{~h} ; \mathrm{Cry}^{2^{-/-}} ; \mathrm{Fbxl3} 3^{\text {Afh/Afh }}\right.$, = $27.83 \pm 0.31 \mathrm{~h}, \Delta=3.59 \mathrm{~h}$ ) and thus stronger in the sole presence of CRY1 than in the sole presence of CRY2 (3.59 vs $1.30 \mathrm{~h}$, respectively) and in wild-types with both CRY1 and CRY2 $(2.8 \mathrm{~h})$. This demonstrates that both CRY1 and CRY2 are mediators of the circadian behavioral actions of $F b x l 3^{A f h}$, which exerts its effects by stabilization of both targets. CRY1, however, is the predominant, more potent endogenous mediator in lengthening the period of behavioral rhythms in mice. We therefore tested the hypothesis that endogenous CRY1 is the predominant transcriptional repressor in the molecular circadian oscillator.

\section{Independent spatiotemporal roles for endogenous CRY1 and CRY2 in transcriptional repression are revealed by Fbxl3 ${ }^{\mathrm{Afh}}$ - dependent stabilization}

The effects of selective stabilization of either CRY1 or CRY2 on circadian behavior likely results from changes in the expression of their target genes. To explore this possibility in biochemically tractable tissues with intrinsic CRY-dependent pacemakers, we investigated the expression of a number of oscillating genes using qPCR across the $24 \mathrm{~h}$ cycle in a well characterized circadian tissue, liver, and in a neural tissue, cerebellum (Fig. 4A, $B$, Table 1). Expression patterns of all genes tested in wild-type controls were robustly rhythmic with the expected phases of expression in both tissues.
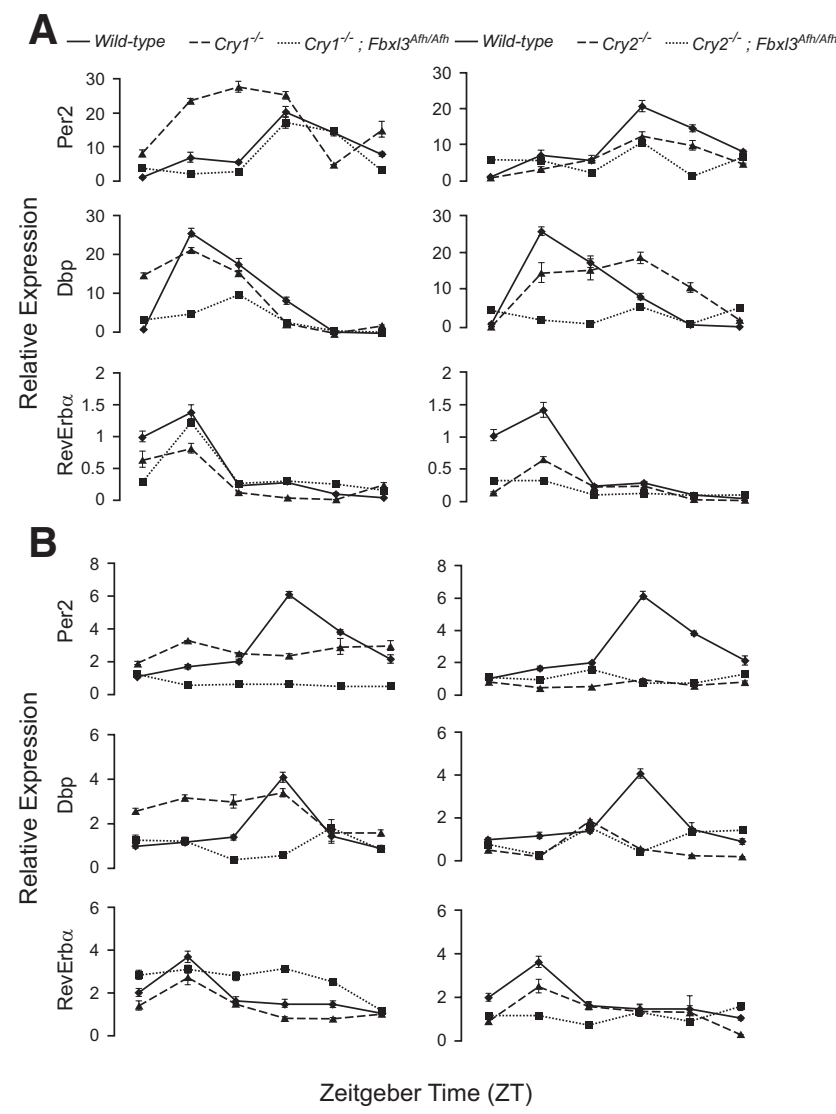

Figure 4. Disruption of circadian gene expression in cerebellum and liver of double mutant mice suggests that $C R Y 1$ is the predominant negative transcriptional regulator. Gene expression values in single and double-mutants are shown for liver $(\boldsymbol{A})$ and cerebellum $(\boldsymbol{B})$ samples across 6 time-points. Values were normalized to Rp/13a and plotted relative to levels in the wild-type sample at ZT3 (assigned an arbitrary value of 1). Each time point is mean from three independent samples (mean \pm SEM, $n=3$ ). Wild-type (solid lines), $\mathrm{Cry}^{-/-}$single mutants (dashed lines), and $\mathrm{Cry}^{-/-} ; \mathrm{Fbx} / 3^{A f h / A f h}$ double mutants (dotted lines).

Clock gene expression in livers of $C r y 1^{-/-}$mice showed no significant changes relative to wild-type controls (two-way ANOVA comparing genotypes across time) while effects in $C r y 1^{-1-} ; F b x l 3^{A f h / A f h}$ double mutants were limited. Although Dbp expression was significantly damped in double mutants $(p=$ 0.002 ), other genes maintained a robust rhythmicity with subtle albeit significant (two-way ANOVA main effects and interaction) changes in the amplitude and phase of expression. In marked contrast, the expression of liver clock genes in the absence of CRY2 was sensitive to the level of CRY1, these being widely and globally suppressed in $C r y 2^{-/-} ;$Fbxl3 $3^{A f h / A f h}$ samples where CRY1 is stabilized. In summary, disturbances in the rhythmic expression of clock genes in the liver highlighted the pronounced ability of endogenous CRY1 to suppress circadian transcription. In contrast, stabilized endogenous CRY2 was relatively impotent in regulating hepatic gene expression rhythms.

In contrast to liver, both cryptochrome proteins were capable of significant transcriptional repression in cerebellum, although CRY1 was the stronger of the two. Undoubtedly, CRY2 can have significant, but more focused, tissue-specific roles in transcriptional regulation. In the absence of CRY1, CRY2 demonstrated subtle effects on gene expression while stabilized CRY2 had a relatively strong effect, with almost complete suppression of Per2 $(p=0.0001)$ and $\operatorname{Dbp}(p=0.008)$ and upregulation of RevErb $\alpha$ $(p=0.001)$. In cerebellum, as in liver, unopposed CRY1 signifi- 


\begin{tabular}{|c|c|c|c|c|c|}
\hline Gene & Genotype effect & Time effect & Genotype*time & Posthoc & \\
\hline $\begin{array}{l}\text { Liver } \\
\qquad \text { Per2 } \\
\text { Dbp } \\
\text { Rev-erbA }\end{array}$ & $\begin{array}{l}F_{(2,36)}=4.231, p=0.022 \\
F_{(2,36)}=15.846, p=0.0001 \\
F_{(2,36)}=4.162, p=0.024\end{array}$ & $\begin{array}{l}F_{(5,36)}=3.861, p=0.007 \\
F_{(5,36)}=20.325, p=0.0001 \\
F_{(5,36)}=25.401, p=0.0001\end{array}$ & $\begin{array}{l}F_{(10,36)}=2.632, p=0.016 \\
F_{(10,36)}=2.208, p=0.040 \\
F_{(5,36)}=3.361, p=0.004\end{array}$ & $\mathrm{Cry}^{-1-}$ & $\begin{array}{l}\mathrm{Cry} 1^{-/-} ; \mathrm{Fb} \times 13^{A f h / A f h} \\
p=0.002\end{array}$ \\
\hline $\begin{array}{l}\text { Per2 } \\
\text { Dbp } \\
\text { Rev-erbA }\end{array}$ & $\begin{array}{l}F_{(2,36)}=9.447, p=0.001 \\
F_{(2,36)}=12.18, p=0.0001 \\
F_{(2,36)}=7.173, p=0.002\end{array}$ & $\begin{array}{l}F_{(5,36)}=4.475, p=0.003 \\
F_{(5,36)}=4.08, p=0.005 \\
F_{(2,36)}=6.347, p=0.0001\end{array}$ & $\begin{array}{l}F_{(10,36)}=3.070, p=0.006 \\
F_{(2,36)}=5.104, p=0.0001\end{array}$ & $\begin{array}{l}\text { Cry } 2^{-1-} \\
p=0.007\end{array}$ & $\begin{array}{l}\text { Cry2 } 2^{-/-} ; F b \times 13^{A f h / A f h} \\
p=0.011 \\
p=0.002 \\
p=0.007\end{array}$ \\
\hline $\begin{array}{l}\text { Cerebellum } \\
\text { Per2 } \\
\text { Dbp } \\
\text { Rev-erbA } \\
\\
\text { Per2 } \\
\text { Dbp } \\
\text { Rev-erbA } \\
\end{array}$ & $\begin{array}{l}F_{(2,36)}=25.077, p=0.001 \\
F_{(2,36)}=27.228, p=0.0001 \\
F_{(2,36)}=14.40, p=0.0001 \\
F_{(2,36)}=7.001, p=0.003 \\
F_{(2,36)}=20.456, p=0.0001 \\
F_{(2,36)}=17.45, p=0.003\end{array}$ & $\begin{array}{l}F_{(5,36)}=2.523, p=0.047 \\
F_{(5,36)}=3.127, p=0.019\end{array}$ & & $\begin{array}{l}\text { Cry } 1^{-1-} \\
p=0.005 \\
p=0.036 \\
p=0.010 \\
\text { Cry } 2^{-1-} \\
p=0.006 \\
p=0.001 \\
p=0.002\end{array}$ & $\begin{array}{l}C r y 1^{-/-} ; F b \times 13^{A f h / A f h} \\
p=0.0001 \\
p=0.008 \\
p=0.001 \\
C r y 2^{-/-} ; F b \times 13^{A f h / A f h} \\
p=0.009 \\
p=0.0001 \\
p=0.0001 \\
\end{array}$ \\
\hline
\end{tabular}

cantly affected the expression of all genes investigated $($ Per $2 p=$ $0.006, D b p p=0.001, \operatorname{RevErb} \alpha p=0.002)$, while these repressive effects were even stronger when CRY1 was stabilized $($ Per $2 p=$ $0.009, D b p p=0.0001, \operatorname{RevErb} \alpha p=0.0001)$.

Thus, while CRY1 is undoubtedly a strong transcriptional repressor, endogenous CRY2 is also confirmed to be a transcriptional repressor, and although it plays a relatively minor role in liver, its repressive effect on gene expression in the cerebellum may serve in unraveling target-specific and tissue-specific roles for CRY2 in the regulation of circadian transcription.

\section{The selective effects of endogenous CRY1 and CRY2 on SCN molecular pacemaking}

Taking the respective behavioral and transcriptional effects of endogenous CRY1 and CRY2 in combination, we sought to test their action within the central pacemaker of the SCN, arguing that differential transcriptional actions of CRY1 and CRY2 would underpin differences in circadian period. $\mathrm{Cry}^{-1-}$ and $\mathrm{Fb} x \mathrm{l} 3^{\mathrm{Afh}}$ mice were therefore intercrossed with the PER2:LUC reporter line (Yoo et al., 2004) to monitor the molecular pacemaker as PER2-driven bioluminescence rhythms in neonatal SCN slice cultures (Fig. 5A,B). All genotypic combinations generated robust, high-amplitude circadian cycles of bioluminescence. Analysis by two-way ANOVA revealed a significant effect for all genotypes $\left(\mathrm{Cry2} 2^{-/-} F_{(2,68)}=134.0, p=0.0001\right.$, Afh $F_{(2,68)}=$ 130.0, $p=0.0001:$ Cry $1^{-/-} F_{(2,80)}=98.1, p=0.0001, A f h F_{(2,80)}=$ $216.2, p=0.0001$ ), although interactions between genotypes did not reach significance. Fbxl3 ${ }^{A f h}$ lengthened SCN bioluminescence rhythms in a dose-dependent fashion (wild-type $=24.20 \pm$ $0.06 \mathrm{~h} ; \mathrm{Fbxl} 3^{\text {Afh/Afh }}=27.01 \pm 0.36 \mathrm{~h}, \Delta=2.81 \mathrm{~h}$ ), whereas $\mathrm{Cry1}^{-/-}$shortened (wild-type $=24.20 \pm 0.06 \mathrm{~h} ; \mathrm{Cry} 1^{-/-}=$ $22.32 \pm 0.12 \mathrm{~h}, \Delta=-1.88 \mathrm{~h}$ ) and $C r y 2^{-/-}$lengthened the period of these rhythms (wild-type $=24.06 \pm 0.10 \mathrm{~h} ; \mathrm{Cry}^{-/-}=$ $26.16 \pm 0.11 \mathrm{~h}, \Delta=2.10 \mathrm{~h}$ ). In double mutants, period lengthening by the $\mathrm{Fb} \times \mathrm{l} 3^{\mathrm{Afh}}$ allele was not as severe in $\mathrm{Cry} \mathrm{1}^{-1-} \mathrm{SCN}$ with stabilized CRY2 $(2.18 \mathrm{~h})$ as it was in CRY wild-type SCN (2.81 h) or in $\mathrm{Cr} y 2^{-/-}$SCN with stabilized CRY1 $(3.50 \mathrm{~h})$. Thus, stabilized endogenous CRY1 and CRY2 can both act independently as decelerators of the SCN molecular pacemaker, and both can mediate the actions of Fbxl3 ${ }^{\mathrm{Afh}}$. Finally, the period of bioluminescence rhythms for each genotype tended to be slightly longer than behavioral rhythms, but, nevertheless, Pearson's correlation from behavioral and slice studies $\left(R^{2}\right.$, Fig. $\left.5 C, D\right)$ indicated a strong correlation $\left(\mathrm{Cryl}^{-/-} ; \mathrm{Fbxl3}{ }^{\text {Afh/Afh }} \mathrm{R}^{2}=0.82, p<0.05\right.$; $\left.C r y 2^{-/-} F b x l 3^{A f h / A f h} R^{2}=0.84, p<0.05\right)$ between the wheel running activity and the SCN slice data in both groups of double mutants across the genotypic range. Thus, although additional potential targets of $F b x l 3^{A f h}$ cannot be excluded from the clockwork, the effects of CRY stabilization at the level of the SCN can nevertheless explain in full the observed behavioral consequences of $F b x / 3^{A f h}$.

To gain further insight into the selective effects of CRY1 and CRY2 on the SCN pacemaker, the normalized bioluminescent waveforms of SCN with the different genotypes were aligned relative to peak PER2::LUC expression levels (Fig. $5 E, F$ ). Such an approach had previously shown that the principal effect of $F b x l 3^{A f h / A f h}$ was to prolong the circadian nadir of PER2::LUC expression, consistent with an extended phase of negative feedback (Godinho et al., 2007). Comparisons of the duration of the PER2::LUC circadian nadir in double mutants confirmed that CRY1 stabilization is predominantly responsible for period lengthening in $F b x l 3^{A f h / A f h}$. While the duration of this trough in $\mathrm{Cry} 1^{-/-} ; \mathrm{Fb} x \mathrm{l} 3^{A f h / A f h} \mathrm{SCN}$ slices (i.e., a CRY2-driven clock) is not significantly different from that of wild-type slices, it is significantly lengthened in $C r y 2^{-/-}$; Fbxl3 $3^{A f h / A f h}$ slices (i.e., a CRY1driven clock) and is comparable to the lengthening seen in Fbxl3 $3^{\text {Afh/Afh }}$ mice. The finding was essentially confirmed when nadir duration was expressed as a percentage of peak duration $(+/+$ $157 \pm 10 \%$, Fbxl3 $^{\text {Afh/Afh }} 188 \pm 16 \%{ }^{* *}, \mathrm{Cryl}^{-/-} ; \mathrm{Fbxl3} \mathrm{3}^{\text {Afh/Afh }} 171 \pm$ $\left.17 \%, C r y 2^{-1-} ; \mathrm{Fbxl3} 3^{\text {Afh/Afh }} 177+7 \%{ }^{\star *} ;{ }^{\star *} p<0.001\right)$. This functional assay thereby provides a clear association between the respective transcriptional activities of endogenous CRY1 and CRY2 and their effects on SCN-dependent circadian behavior in $\mathrm{Fbxl3}$ wild-type and $\mathrm{Fbxl} 3^{\mathrm{Afh}}$ backgrounds.

\section{Circadian stabilization of mouse cryptochromes is both necessary and sufficient to account for the Fbxl3 ${ }^{\mathrm{Afh} / \mathrm{Afh}}$ period-lengthening phenotype}

Although the wheel-running behavior in $\mathrm{Cry1}^{-/-} ; \mathrm{Cry}^{-/-}$double mutants shows a $24 \mathrm{~h}$ rhythm under a light/dark cycle, this effect is due to the masking effect of light on locomotor activity in a nocturnal rodent. In contrast, in constant darkness the Cry $1^{-1-}$; Cry $2^{-/-}$double mutants were totally arrhythmic (Vitaterna et al., 1999; van der Horst et al., 1999). To determine whether cryptochromes are solely responsible for the periodlengthening phenotype in $\mathrm{Fb} x \mathrm{l} 3^{A f h / A f h}$ mice, we generated $\mathrm{Fbxl3} 3^{\text {Afh/Afh }} ; \mathrm{Cry} 1^{-/-} ; \mathrm{Cry} 2^{-/-}$triple mutant mice and confirmed 
A
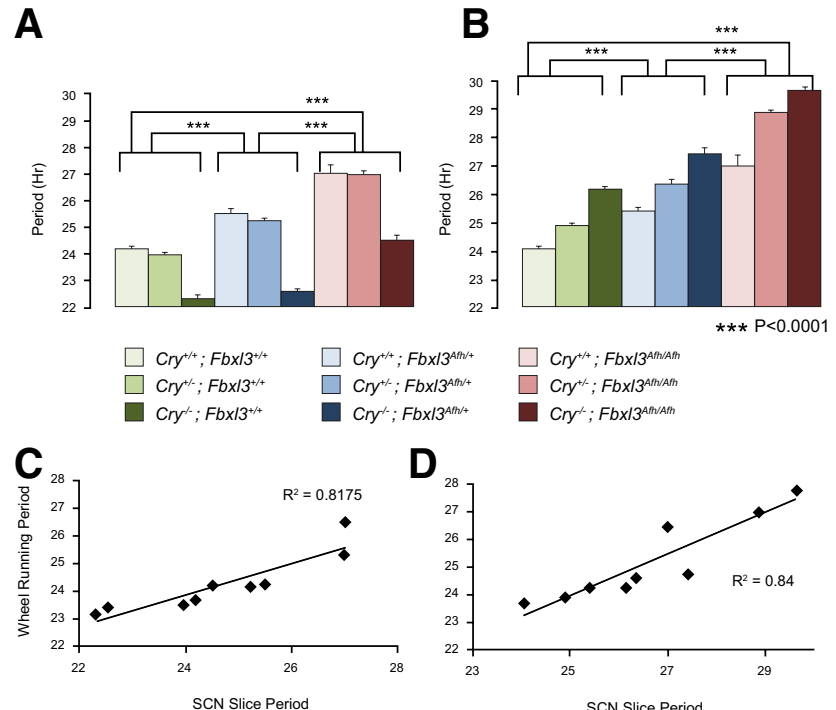

E

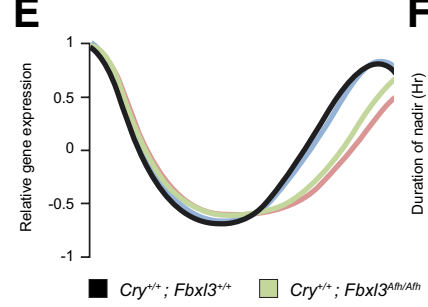

\section{$F$ \\ $F_{0}$}
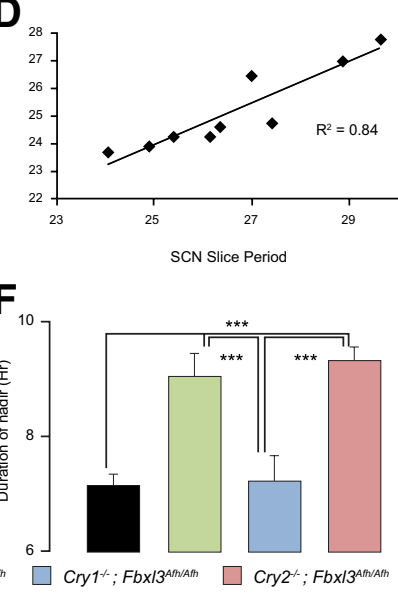

Figure 5. Measurement of bioluminescence rhythms in the $\mathrm{SCN}$ of double mutants further defines the contribution of CRY1 to molecular pacemaking. Grouped data (mean \pm SEM) comparing the period of PER2::Iuc bioluminescence rhythms for all genotype combinations of $\mathrm{Cry} 1^{-/-} ; \mathrm{Fbx} / 3^{A f h / A f h}(\boldsymbol{A})$ and $\mathrm{Cry} 2^{-/-} ; \mathrm{Fbx} / 3^{\text {Afh/Afh }}(\boldsymbol{B})$ double mutant crosses, ${ }^{* *} p<0.05$, ${ }^{* * *} p<0.01$. Significant post hoc results from two-way ANOVA have been shown for $\mathrm{Fb} \times 13^{A f h}$ only, whereas the post hoc for Cry are the same as the wheel-running behavior. Correlation, for all 9 genotypic combinations, between period length in vitro in $\mathrm{SCN}$ slices and in vivo wheelrunning behavior in (C) $\mathrm{Cry} 1^{-/-} ; \mathrm{Fb} \times 13^{A f h / A t h}$ and (D) $\mathrm{Cry} 2^{-/-} ; \mathrm{Fb} \times 3^{A \text { Afh/Ath }}$ double mutant crosses. Pearson's correlation coefficient $\left(R^{2}\right)$ shows a high degree of correlation between the two groups of data in both sets of mutants. $\boldsymbol{E}$, Circadian waveform normalized plots of bioluminescence curves (mean \pm SEM) from wild-type (black, $n=7$ ), Fbx/3 $3^{\text {Afh/Afh }}$ (green, $n=11$ ), $\mathrm{Cry}^{-1-} ; \mathrm{Fbx} 13^{\text {Aft/Afh }}$ (blue, $n=10$ ), and $\mathrm{Cry} 2^{-1-} ; \mathrm{Fbx} 13^{\text {Ath/Afh }}(\mathrm{red}, n=8)$ double homozygous $S C N$ slices, aligned by peak expression. $F$, Group data (mean \pm SEM) for the duration of the interval of basal bioluminescence (duration of curve below level corresponding to $20 \%$ above nadir) from wild-type (black, $n=7)$, Fbx $13^{A f h / A f h}$ homozygous (green, $\left.n=11\right)$, $\left(r y 1^{-1-}\right.$; Fbx/ $3^{\text {Afh/Afh }}$ (blue, $n=10$ ), and $C r y 2^{-1-} ; F b x / 3^{\text {Aft/Afh }}($ red, $n=8$ ) double homozygous SCN slices. Statistical significance was determined by one-way ANOVA with Bonferroni post hoc analysis, ${ }^{* * *} p<0.01$.

that triple mutant mice were also behaviorally arrhythmic (Fig. $6 A, B)$. Moreover, there were no observable additional consequences of $\mathrm{Fbxl} 3^{A f h}$ for circadian behavior. Thus, the circadian stabilization of mouse cryptochromes is necessary to express the Fbxl3 ${ }^{\text {Afh/Afh }}$ circadian behavioral phenotype in vivo. Recently, however, we discovered that $\mathrm{Cr} y 1^{-/-} ; \mathrm{Cry}^{-/-} \mathrm{SCN}$ can express intrinsic CRY-independent molecular pacemaking with an extremely short period of $\sim 18 \mathrm{~h}$, albeit highly variable and unstable (Maywood et al., 2011a). It is possible that these intrinsic rhythms could be driven exclusively by PER-mediated transcriptional feedback but equally likely that these rhythms could be maintained through intracellular signaling systems (such as $\mathrm{Ca}^{2+}$ or cAMP) independent of any transcriptional/posttranslational feedback loop (Hastings et al., 2008). These findings are not unprecedented, being similar to results obtained using SCN from the Bmal1 $^{-/-}$behaviorally arrhythmic model (Ko et al., 2010). In the current study, therefore, representative examples of slices ex-
A
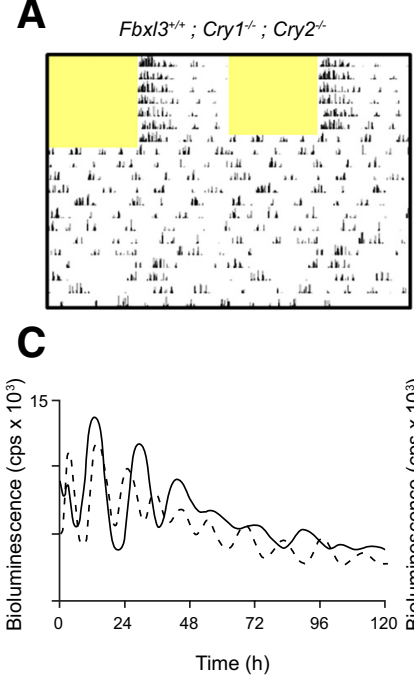

E

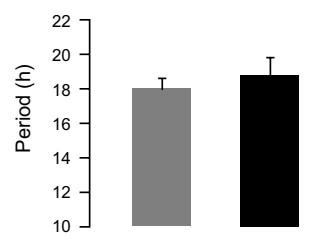

B $\mathrm{Fbx} / 3^{\mathrm{Afh} / \mathrm{Ath}} ; \mathrm{Cry} 1^{\%} ; \mathrm{Cry} 2^{-}$

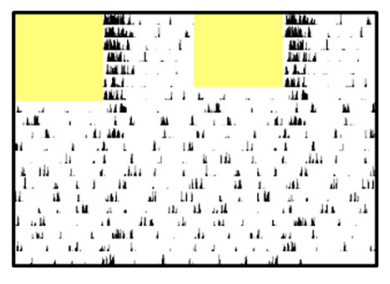

D

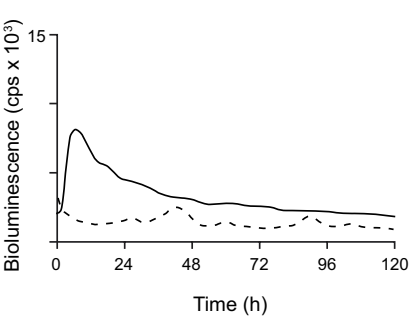

$\mathbf{F}$

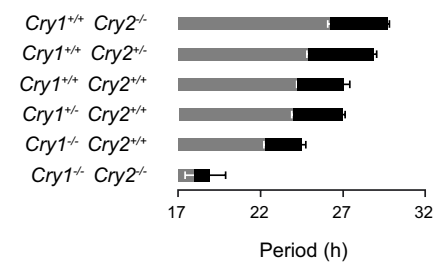

Figure 6. An intrinsic CRY-independent pacemaker in $\mathrm{SCN}$ is extremely short, unstable, and is unaffected by $\mathrm{Fb} \times 13^{A f t}$. Double plotted actograms depicting behavioral arrhythmicity in $\mathrm{Cry} 1^{-/-} ; \mathrm{Cry}^{-/-}$double $(\boldsymbol{A})$ and $\mathrm{Cry} 1^{-/-} ; \mathrm{Cry}^{-/-} ; \mathrm{Fb} \times 13^{\text {Afth/Afh }}(\boldsymbol{B})$ triple mutants. Addition of $F b x / 3^{A f h / A t h}$ has no consequences on the arrhythmic phenotype in $\mathrm{Cry}^{-1-} ; \mathrm{Cry}^{-1-}$ mice. In SCN slices expressing Per2::Luc bioluminescence, $\sim 60 \%$ of slices from both double (solid lines) and triple mutants (dashed lines) can maintain a rhythm for several days $(\boldsymbol{C})$ although many slices exhibit unstable rhythms or arrhythmicity (D). Rhythmic slices express an intrinsic rhythm $(\boldsymbol{E})$ that is extremely short in $\mathrm{Cry}^{-/-}$; $\mathrm{Cry2} 2^{-/-}$slices (gray, $18.03 \pm 0.60 \mathrm{~h}$, $n=10$ ) and is not affected by the presence of $F b x / 3^{A f h / A f h}$ (black, $\left.18.92 \pm 0.94 \mathrm{~h}, n=10\right) . F$, A schematic representation of the proposed effects of CRY1, CRY2, and CRY1 and CRY2 in combination upon the intrinsic $\sim 18 \mathrm{~h}$ period of the $\mathrm{SCN}$ in the absence of cryptochromes. Period length can be variably lengthened by the addition of CRY2 and/or CRY1 (horizontal gray bars with white error bars) with further lengthening to a maximum of $\sim 30 \mathrm{~h}$ when combinations of Cry alleles are stabilized in the presence of $F b x / 3^{A f h}$ (horizontal black bar extensions with black error bars). These combined results would suggest that, contrary to what has previously been proposed, CRY2 functions as a clock decelerator but is less efficient and antagonistic to the actions of CRY1 on clock speed.

pressing both rhythmic and arrhythmic bioluminescence were recorded (Fig. 6C,D), and $\sim 58 \%(10 / 17)$ of all Cry $1^{-/-}$; Cry $2^{-/-}$ slices recorded were rhythmic with a period of $18.03 \pm 0.60 \mathrm{~h}$ (Fig. $6 E$ ). This intrinsic pacemaker rhythm was also evident in the presence of $F b x l 3^{A f h / A f h}$ with $\sim 61 \%(8 / 13)$ of $F b x l 3^{A f h / A f h}$; Cry $1^{-/-}$; Cry $2^{-/-}$slices expressing bioluminescence oscillations. Importantly, their period of $18.92 \pm 0.94 \mathrm{~h}$ was not significantly different from that seen in CRY-deficient slices with wild-type Fbxl3 background. The lack of effect on the intrinsic $C r y 1^{-/-}$; $C r y 2^{-1-}$ SCN pacemaker demonstrates that the circadian stabilization of mouse cryptochromes is necessary and sufficient to express the $\mathrm{Fb} x \mathrm{l} 3^{\mathrm{Afh} / \mathrm{Afh}}$ phenotype; i.e., Fbxl3 ${ }^{\mathrm{Afh}}$ has no mediators of its circadian actions other than CRY1 and CRY2. Moreover, it would appear that even though $\mathrm{Cry} \mathrm{1}^{-1-} ; \mathrm{Cry} 2^{-/-}$mice can maintain a rhythm in the SCN, they are unable to coordinate rhythms in circadian output measures, hence they are behaviorally arrhythmic. 


\section{Discussion}

Through the generation of double mutants that maintain stable protein levels of one CRY in the absence of its paralogue, we have demonstrated differential and selective contributions of endogenous CRY1 and CRY2 proteins in defining the pace of the SCN circadian clock and its circadian transcriptional outputs. Specifically, we have established that CRY1 is a more potent transcriptional suppressor of endogenous target genes in cerebellum and liver than is CRY2, and correspondingly that it is more effective than CRY2 in lengthening the period of the SCN oscillator through a more prolonged duration of E-box-mediated transcriptional repression during circadian night. Notwithstanding its less potent but nevertheless real transcriptional activity, endogenous CRY2 has a critical role in tuning SCN circadian period by opposing the action of CRY1. Moreover, we have shown that, although there are potentially additional targets of FBXL3, stabilization of CRY1 and CRY2 is both necessary and sufficient to account for the Fbl $x 3^{A f h}$ period-lengthening phenotype. Finally, our analysis of the $C r y 1^{-/-} ; C r y 2^{-/-} ; F b x l 3^{A f h / A f h}$ compound phenotype revealed a spontaneous, short period, CRY- and FBXL3independent pacemaking activity in the SCN, which in the wild-type SCN is tuned to $24 \mathrm{~h}$ by CRY2 titrating the action of the more efficient clock decelerator CRY1.

Our findings on differential CRY1 and CRY2 contributions to SCN circadian timing and output rhythms in liver and cerebellum provide an in vivo context to interpret recent data on the transcriptional architecture of the circadian feedback loop using ChIP-seq in mouse liver. In both SCN and liver, expression of CRY1 and CRY2 is circadian, protein levels accumulating in parallel during late circadian day and into circadian night (Kume et al., 1999; Lee et al., 2001; Koike et al., 2012). Despite common changes in abundance, their interactions with DNA regulatory elements show contrasting temporal profiles. Whereas occupancy by CRY2 starts to increase from early circadian day and peaks in early circadian night (CT16), coincident with associated PER-mediated transcriptional repression, CRY1 binding starts in later circadian night (CT20) with a peak at circadian dawn (CT0). A particular property ascribed to CRY1 is the extension of the repression phase into the next circadian cycle, holding off CLOCK:BMAL transcriptional activation in an otherwise "poised" state (Koike et al., 2012). The mild transcriptional inhibition we have revealed for endogenous CRY2 likely corresponds to its time-limited occupancy of target elements, coincident with, and possibly facilitated by, PER proteins. Its titration of CRY1mediated feedback may arise from this occupancy-CRY2 denying CRY1 early access to its DNA targets. On the other hand, CRY1 repression appears to have an autonomous, open-ended action, independent of PER and CRY2 activity that extends into circadian day. Thus, its stabilization by $F b x l 3^{A f h}$ enables it to delay the onset of transactivation by transcriptionally poised CLOCK/ BMAL, thereby potently extending the interval of negative feedback. This new perspective on DNA-occupancy by CRY1 also provides a molecular explanation for another phenotype of $F b x l 3^{A f h}$ : the additive effects of the Fbxl3 ${ }^{A f h}$ and Casein Kinase $1 \varepsilon$ Tau (CK1 $\left.\varepsilon^{\text {Tau }}\right)$ mutations (Maywood et al., 2011b). CK1 $\varepsilon^{\text {Tau }}$ accelerates circadian behavior and SCN pacemaking by destabilizing PER proteins, facilitating their early degradation and thereby truncating their interval of negative transcriptional feedback. In mice carrying both $F b x l 3^{A f h}$ and $C K 1 \varepsilon^{T a u}$ mutations, the circadian period is determined by their additive contributions - there is no evidence of epistasis between them. Thus, the $C K 1 \varepsilon^{T a u}$ and $F b x l 3^{A f h}$ alleles independently shorten and lengthen the PER- dominated and CRY1-dominated intervals of transcriptional inhibition, respectively, in circadian night and early circadian day.

The differential contributions of CRY1 and CRY2 to transcriptional feedback also have relevance for clock-controlled outputs, the effectors of circadian behavior and physiology. In the absence of Cry1 (in a CRY2-driven clock), there were subtle tissue-specific and target-specific effects on transcription. CRY2 shows a minimal effect in liver regardless of whether it has been stabilized by Fbxl3 ${ }^{A f h}$. In cerebellum, CRY2 basal effects are more pronounced and this is more apparent when CRY2 is stabilized. On the other hand, in the absence of CRY2, in a CRY1-driven clock, there is an almost universal transcriptional repression of clock-controlled genes, particularly so when CRY1 is stabilized by $F b x l 3^{A f h}$. The results strongly indicate that endogenous CRY proteins may have distinct roles in transcriptional complexes in different mammalian tissues. Such a role has previously been suggested for the circadian transcriptional repressors SHARP-1 (DEC2) and SHARP-2 (STRA13/DEC1) (Rossner et al., 2008).

One important feature that distinguishes the current study of CRY function from other studies is the focus on physiologically relevant changes that incorporate all of the necessary processes modifying CRY function in vivo. In contrast, overexpression studies of recombinant proteins in vitro have yielded conflicting views on CRY functions in the oscillator (Ueda et al., 2005; Fan et al., 2007; Liu et al., 2007; Yamanaka et al., 2007; Khan et al., 2012). This could be related to the differences in promoters used in expression constructs or in cells or tissues used to determine oscillator effects, but could equally likely be related to the fact that these systems cannot account for all of the modifications and subcellular trafficking that CRY proteins must undergo during the course of the SCN circadian cycle (Eide et al., 2002; Hirayama et al., 2003; Sanada et al., 2004; Harada et al., 2005; Chaves et al., 2006; Hitomi et al., 2009; Lamia et al., 2009; McCarthy et al., 2009). Nevertheless, our observations that stabilization of either CRY1 or CRY2 can lengthen period have recently been replicated through the use of a novel small molecule that appears to phenocopy the Fbxl3 $3^{\text {Afh }}$ mutation by stabilizing CRY proteins (Hirota et al., 2012). In addition, an in silico mathematical model used by the same group (Hirota et al., 2012) predicted our experimentally derived conclusions from in vivo studies that stabilization of CRY2 in the absence of CRY1 can lengthen circadian period.

Our data from wheel-running and SCN oscillations show that stabilization of CRY2 can slow the clock, whereas mice that are homozygous null for Cry2 also have a slower clock [the present study and data from the studies by Vitaterna et al. (1999); van der Horst et al. (1999)]. This is in some ways a paradoxical result. How might the absence of CRY2 and the stabilization of CRY2 have the same overall phenotypic effect? This paradox is resolved, however, by considering the summary of genetic interactions between Cry and Fbxl3 mutations in SCN slices (Fig. 6F), which confirmed that in the "ground state" of $\mathrm{Cr} y 1^{-/-}$; $\mathrm{Cr} y 2^{-/-}, \mathrm{SCN}$ slices express an intrinsic period of $\sim 18 \mathrm{~h}$. Addition of CRY2 and CRY1 together lengthens this period to a wild-type condition of $\sim 24 \mathrm{~h}$. Restoration of CRY2 alone, however, is less effective and so a CRY1-null SCN, expressing only CRY2, has a period shorter than wild-type, but nevertheless longer than the doubly CRYdeficient ground state. Conversely, restoration of CRY1 alone, in the absence of CRY2, is even more effective and the period is longer than the wild-type condition. This comparison further demonstrates that CRY2 (in the wild-type context) attenuates the potent effect of CRY1, generating a wild-type period of $\sim 24 \mathrm{~h}$. Thus, it is this interaction of CRY1 and CRY2 that leads to the 
paradoxical observation that loss of the negative regulator CRY2 lengthens the period of the clock. It does so because it unmasks the unopposed effects of the more potent regulator, CRY1. Contrary to our current understanding of clock function, therefore, endogenous CRY2 is not an "accelerator" of the clock-it is simply a less effective decelerator of the intrinsic CRY-free clock, but nevertheless one that competes with endogenous CRY1 and suppresses the more potent action of CRY1 on pacemaking. In support of this observation, period lengthening can be achieved by the stabilization of either CRY in the presence of $F b x l 3^{A f h / A f h}$, although this effect is stronger when CRY1 rather than CRY2 is stabilized. The bioluminescence data provide clear evidence of these differential effects of CRY1 and CRY2. By aligning waveforms of PER2::LUC activity, the interval of negative feedback was assessed by measuring the duration of the nadir of PER2::LUC expression. Previously, we have shown that the $F b \times l 3^{A f h}$ mutation acts via extending the duration of this nadir (Godinho et al., 2007). Our current findings show that selective stabilization of CRY1 is the principal mediator of period lengthening in the SCN. These results complement the early behavioral findings (van der Horst et al., 1999) that the effects of CRY2 on circadian regulation are sensitive to the dosage of CRY1.

The description of CRY-independent oscillation in the SCN extends previous reports in CRY-null and Bmal1 ${ }^{-1-}$ SCN slices (Ko et al., 2010; Maywood et al., 2011a), which argue that the SCN can sustain intrinsic rhythms independently of the transcriptional oscillator. These are likely to be mediated through intercellular and intracellular signaling oscillations involving cAMP and $\left[\mathrm{Ca}^{2+}\right]_{\mathrm{i}}$. However, although molecular oscillations can remain rhythmic in $\mathrm{Cry} 1^{-1-} ; \mathrm{Cry}^{-1-} \mathrm{SCN}$ in the absence of CRY1 and CRY2 to control output pathways, circadian information cannot be effectively relayed to other brain regions and peripheral organs, thus explaining the immediate and complete behavioral arrhythmicity seen in the $\mathrm{Cr} y 1^{-/-} ; \mathrm{Cr} y 2^{-/-}$ mouse.

\section{References}

Bacon Y, Ooi A, Kerr S, Shaw-Andrews L, Winchester L, Breeds S, TymoskaLalanne Z, Clay J, Greenfield AG, Nolan PM (2004) Screening for novel ENU-induced rhythm, entrainment and activity mutants. Genes Brain Behav 3:196-205. CrossRef Medline

Barnard AR, Nolan PM (2008) When clocks go bad: neurobehavioural consequences of disrupted circadian timing. PLoS Genet 4:e1000040. CrossRef Medline

Brown SA, Kowalska E, Dallmann R (2012) (Re)inventing the circadian feedback loop. Dev Cell 22:477-487. CrossRef Medline

Chaves I, Yagita K, Barnhoorn S, Okamura H, van der Horst GT, Tamanini F (2006) Functional evolution of the photolyase/cryptochrome protein family: importance of the $\mathrm{C}$ terminus of mammalian CRY1 for circadian core oscillator performance. Mol Cell Biol 26:1743-1753. CrossRef Medline

Delezie J, Challet E (2011) Interactions between metabolism and circadian clocks: reciprocal disturbances. Ann N Y Acad Sci 1243:30-46. CrossRef Medline

Eide EJ, Vielhaber EL, Hinz WA, Virshup DM (2002) The circadian regulatory proteins BMAL1 and cryptochromes are substrates of casein kinase Iepsilon. J Biol Chem 277:17248-17254. CrossRef Medline

Fan Y, Hida A, Anderson DA, Izumo M, Johnson CH (2007) Cycling of CRYPTOCHROME proteins is not necessary for circadian-clock function in mammalian fibroblasts. Curr Biol 17:1091-1100. CrossRef Medline

Godinho SI, Maywood ES, Shaw L, Tucci V, Barnard AR, Busino L, Pagano M, Kendall R, Quwailid MM, Romero MR, O’Neill J, Chesham JE, Brooker D, Lalanne Z, Hastings MH, Nolan PM (2007) The after-hours mutant reveals a role for Fbxl3 in determining mammalian circadian period. Science 316:897-900. CrossRef Medline

Griffin EA Jr, Staknis D, Weitz CJ (1999) Light-independent role of CRY1 and CRY2 in the mammalian circadian clock. Science 286:768-771. CrossRef Medline

Harada Y, Sakai M, Kurabayashi N, Hirota T, Fukada Y (2005) Ser-557phosphorylated mCRY2 is degraded upon synergistic phosphorylation by glycogen synthase kinase-3 beta. J Biol Chem 280:31714-31721. CrossRef Medline

Hastings MH, Maywood ES, O’Neill JS (2008) Cellular circadian pacemaking and the role of cytosolic rhythms. Curr Biol 18:R805-R815. CrossRef Medline

Hirayama J, Nakamura H, Ishikawa T, Kobayashi Y, Todo T (2003) Functional and structural analyses of cryptochrome. Vertebrate CRY regions responsible for interaction with the CLOCK:BMAL1 heterodimer and its nuclear localization. J Biol Chem 278:35620-35628. CrossRef Medline

Hirota T, Lee JW, St John PC, Sawa M, Iwaisako K, Noguchi T, Pongsawakul PY, Sonntag T, Welsh DK, Brenner DA, Doyle FJ 3rd, Schultz PG, Kay SA (2012) Identification of small molecule activators of cryptochrome. Science 337:1094-1097. CrossRef Medline

Hitomi K, DiTacchio L, Arvai AS, Yamamoto J, Kim ST, Todo T, Tainer JA, Iwai S, Panda S, Getzoff ED (2009) Functional motifs in the (6-4) photolyase crystal structure make a comparative framework for DNA repair photolyases and clock cryptochromes. Proc Natl Acad Sci U S A 106: 6962-6967. CrossRef Medline

Kennaway DJ, Boden MJ, Varcoe TJ (2012) Circadian rhythms and fertility. Mol Cell Endocrinol 349:56-61. CrossRef Medline

Khan SK, Xu H, Ukai-Tadenuma M, Burton B, Wang Y, Ueda HR, Liu AC (2012) Identification of a novel cryptochrome differentiating domain required for feedback repression in circadian clock function. J Biol Chem 287:25917-25926. CrossRef Medline

Ko CH, Yamada YR, Welsh DK, Buhr ED, Liu AC, Zhang EE, Ralph MR, Kay SA, Forger DB, Takahashi JS (2010) Emergence of noise-induced oscillations in the central circadian pacemaker. PLoS Biol 8:e1000513. CrossRef Medline

Koike N, Yoo SH, Huang HC, Kumar V, Lee C, Kim TK, Takahashi JS (2012) Transcriptional architecture and chromatin landscape of the core circadian clock in mammals. Science 338:349-354. CrossRef Medline

Kume K, Zylka MJ, Sriram S, Shearman LP, Weaver DR, Jin X, Maywood ES, Hastings MH, Reppert SM (1999) mCRY1 and mCRY2 are essential components of the negative limb of the circadian clock feedback loop. Cell 98:193-205. CrossRef Medline

Lamia KA, Sachdeva UM, DiTacchio L, Williams EC, Alvarez JG, Egan DF, Vasquez DS, Juguilon H, Panda S, Shaw RJ, Thompson CB, Evans RM (2009) AMPK regulates the circadian clock by cryptochrome phosphorylation and degradation. Science 326:437-440. CrossRef Medline

Lee C, Etchegaray JP, Cagampang FR, Loudon AS, Reppert SM (2001) Posttranslational mechanisms regulate the mammalian circadian clock. Cell 107:855-867. CrossRef Medline

Liu AC, Welsh DK, Ko CH, Tran HG, Zhang EE, Priest AA, Buhr ED, Singer O, Meeker K, Verma IM, Doyle FJ 3rd, Takahashi JS, Kay SA (2007) Intercellular coupling confers robustness against mutations in the SCN circadian clock network. Cell 129:605-616. CrossRef Medline

Logan RW, Sarkar DK (2012) Circadian nature of immune function. Mol Cell Endocrinol 349:82-90. CrossRef Medline

Looby P, Loudon AS (2005) Gene duplication and complex circadian clocks in mammals. Trends Genet 21:46-53. CrossRef Medline

Maywood ES, Reddy AB, Wong GK, O’Neill JS, O’Brien JA, McMahon DG, Harmar AJ, Okamura H, Hastings MH (2006) Synchronization and maintenance of timekeeping in suprachiasmatic circadian clock cells by neuropeptidergic signaling. Curr Biol 16:599-605. CrossRef Medline

Maywood ES, Chesham JE, O'Brien JA, Hastings MH (2011a) A diversity of paracrine signals sustains molecular circadian cycling in suprachiasmatic nucleus circuits. Proc Natl Acad Sci U S A 108:14306-14311. CrossRef Medline

Maywood ES, Chesham JE, Meng QJ, Nolan PM, Loudon AS, Hastings MH (2011b) Tuning the period of the mammalian circadian clock: additive and independent effects of CKlepsilonTau and Fbxl3Afh mutations on mouse circadian behavior and molecular pacemaking. J Neurosci 31: 1539-1544. CrossRef Medline

McCarthy EV, Baggs JE, Geskes JM, Hogenesch JB, Green CB (2009) Generation of a novel allelic series of cryptochrome mutants via mutagenesis reveals residues involved in protein-protein interaction and CRY2specific repression. Mol Cell Biol 29:5465-5476. CrossRef Medline

Rossner MJ, Oster H, Wichert SP, Reinecke L, Wehr MC, Reinecke J, Eichele 
G, Taneja R, Nave KA (2008) Disturbed clockwork resetting in Sharp-1 and Sharp-2 single and double mutant mice. PLoS One 3:e2762. CrossRef Medline

Sanada K, Harada Y, Sakai M, Todo T, Fukada Y (2004) Serine phosphorylation of $\mathrm{mCRY} 1$ and $\mathrm{mCRY} 2$ by mitogen-activated protein kinase. Genes Cells 9:697-708. CrossRef Medline

Sehgal A, Mignot E (2011) Genetics of sleep and sleep disorders. Cell 146: 194-207. CrossRef Medline

Siepka SM, Yoo SH, Park J, Lee C, Takahashi JS (2007) Genetics and neurobiology of circadian clocks in mammals. Cold Spring Harb Symp Quant Biol 72:251-259. CrossRef Medline

Ueda HR, Hayashi S, Chen W, Sano M, Machida M, Shigeyoshi Y, Iino M, Hashimoto S (2005) System-level identification of transcriptional circuits underlying mammalian circadian clocks. Nat Genet 37:187192. CrossRef Medline

van der Horst GT, Muijtjens M, Kobayashi K, Takano R, Kanno S, Takao M, de Wit J, Verkerk A, Eker AP, van Leenen D, Buijs R, Bootsma D, Hoeijmakers JH, Yasui A (1999) Mammalian Cry1 and Cry2 are essential for maintenance of circadian rhythms. Nature 398:627-630. CrossRef Medline

Vitaterna MH, Selby CP, Todo T, Niwa H, Thompson C, Fruechte EM, Hitomi K, Thresher RJ, Ishikawa T, Miyazaki J, Takahashi JS, Sancar A (1999) Differential regulation of mammalian period genes and circadian rhythmicity by cryptochromes 1 and 2. Proc Natl Acad Sci U S A 96: 12114-12119. CrossRef Medline

Yamanaka I, Koinuma S, Shigeyoshi Y, Uchiyama Y, Yagita K (2007) Presence of robust circadian clock oscillation under constitutive overexpression of mCryl in rat-1 fibroblasts. FEBS Lett 581:40984102. CrossRef Medline

Yoo SH, Yamazaki S, Lowrey PL, Shimomura K, Ko CH, Buhr ED, Siepka SM, Hong HK, Oh WJ, Yoo OJ, Menaker M, Takahashi JS (2004) PERIOD2::LUCIFERASE real-time reporting of circadian dynamics reveals persistent circadian oscillations in mouse peripheral tissues. Proc Natl Acad Sci U S A 101:5339-5346. Epub 2004 Feb 5312. CrossRef Medline 